\title{
LncRNAs: the bridge linking RNA and colorectal cancer
}

Review

\author{
Yanfei Yang ${ }^{1, *}$, Linjie Zhao ${ }^{1, *}$, Lingzi Lei ${ }^{1, *}$, Wayne Bond Lau ${ }^{2, *}$, Bonnie Lau ${ }^{3, *}$, Qilian \\ Yang ${ }^{1}$, Xiaobing Le ${ }^{1}$, Huiliang Yang ${ }^{4}$, Chenlu Wang ${ }^{5}$, Zhongyue Luo ${ }^{5}$, Yu Xuan ${ }^{1}$, \\ Yi Chen ${ }^{6}$, Xiangbing Deng ${ }^{6}$, Lian Xu' ${ }^{7}$, Min Feng ${ }^{7}$, Tao $\mathrm{Yi}^{1}{ }^{1}$, Xia Zhao ${ }^{1}$, Yuquan Wei ${ }^{1}$, \\ Shengtao Zhou ${ }^{1}$ \\ ${ }^{1}$ Department of Obstetrics and Gynecology, Key Laboratory of Birth Defects and Related Diseases of Women and Children of \\ Ministry of Education, West China Second Hospital and State Key Laboratory of Biotherapy/Collaborative Innovation Center, \\ West China Hospital, Sichuan University, Chengdu, P. R. China \\ ${ }^{2}$ Department of Emergency Medicine, Thomas Jefferson University Hospital, U.S.A \\ ${ }^{3}$ Department of Emergency Medicine, Kaiser Permanente Santa Clara Medical Center, Affiliate of Stanford University, U.S.A \\ ${ }^{4}$ Department of Orthopedics, West China Hospital, Sichuan University, Chengdu, P. R. China \\ ${ }^{5}$ College of Life Sciences, Sichuan University, Chengdu, P. R. China \\ ${ }^{6}$ Department of Gastrointestinal Surgery, West China Hospital, Sichuan University, Chengdu, P.R. China \\ ${ }^{7}$ Department of Pathology, West China Second Hospital, Sichuan University, Chengdu, P. R. China \\ *These authors have contributed equally to this work \\ Correspondence to: Shengtao Zhou, email: taotaovip2005@163.com \\ Keywords: IncRNAs, colorectal cancer, proliferation, angiogenesis, metastasis \\ Received: May 20, $2016 \quad$ Accepted: November 12, $2016 \quad$ Published: November 24, 2016
}

\section{ABSTRACT}

Long noncoding RNAs (IncRNAs) are transcribed by genomic regions (exceeding 200 nucleotides in length) that do not encode proteins. While the exquisite regulation of IncRNA transcription can provide signals of malignant transformation, IncRNAs control pleiotropic cancer phenotypes through interactions with other cellular molecules including DNA, protein, and RNA. Recent studies have demonstrated that dysregulation of IncRNAs is influential in proliferation, angiogenesis, metastasis, invasion, apoptosis, stemness, and genome instability in colorectal cancer (CRC), with consequent clinical implications. In this review, we explicate the roles of different IncRNAs in CRC, and the potential implications for their clinical application.

\section{INTRODUCTION}

Colorectal cancer is a frequently diagnosed and fatal malignancy worldwide, with nearly 1.4 million newly diagnosed cases in 2012 [1]. The conventional chemotherapeutic strategies for CRC involve the use of highly toxic drugs, which cause undesirable side-effects [2]. It is therefore important to identify both novel biomarkers and therapies for early diagnosis and improved treatment.

Recently, the genomics has identified unexpected non-protein coding regions of the genome. The list of long noncoding RNAs (lncRNAs), functionally defined as transcripts $>200 \mathrm{nt}$ in length with no protein-coding potential, continues to grow. Researchers have discovered many of these lncRNAs are uniquely expressed in differentiated tissues or specific cancer types. It is now established that lncRNAs are exquisitely controlled and are restricted to specific cell types to a greater degree than mRNA [3]. They frequently have evolutionarily conserved function, secondary structure, and regions of microhomology, despite minimal overall sequence similarity [4]. However, the functions of the vast majority of these transcripts remain unknown. Evidence supports the important role lncRNAs perform in CRC (Figure 1), via incompletely understood mechanisms. In this review, we comprehensively detail the functional roles of lncRNAs in maintaining the hallmarks of malignancy in colorectal cancer, and their potential clinical applications in the treatment of CRC (Table 1).

\section{SUSTAINING PROLIFERATION}

In normal tissue, the production and release of cellular growth signals is tightly controlled, ensuring homeostasis and balance in the cellular population. 
Dysregulation of such signaling leads to malignancy. Uncontrolled gene transcription with resultant protein production may increase cellular proliferation, but excess proliferative signaling may in turn trigger cellular senescence. Cancer cells may also sustain proliferation by evading growth suppressors. For instance, the RB protein is pivotal in negative control of the cell cycle and tumor progression. TP53 proteins control cellular division and prevent uncontrolled growth-and-division by activating apoptosis and preventing cell-cycle progression [5]. In recent years, the role of lncRNAs in sustaining proliferation of CRC cells has garnered great interest (Table 2).

LncRNA colon cancer-associated transcript 1(CCAT1) is a recently discovered 2628 nucleotideIncRNA, located in the vicinity of c-Myc. He et al discovered that c-Myc could promote CCAT1 transcription by directly binding to its promoter region, and enhanced CCAT1 expression in CRC cells cells increased cell proliferation and invasion [6]. Moreover, Takahashi et al reported lncRNA Plasmacytoma variant translocation 1 (PVT-1) expression is increased by amplification of $8 \mathrm{q} 24$

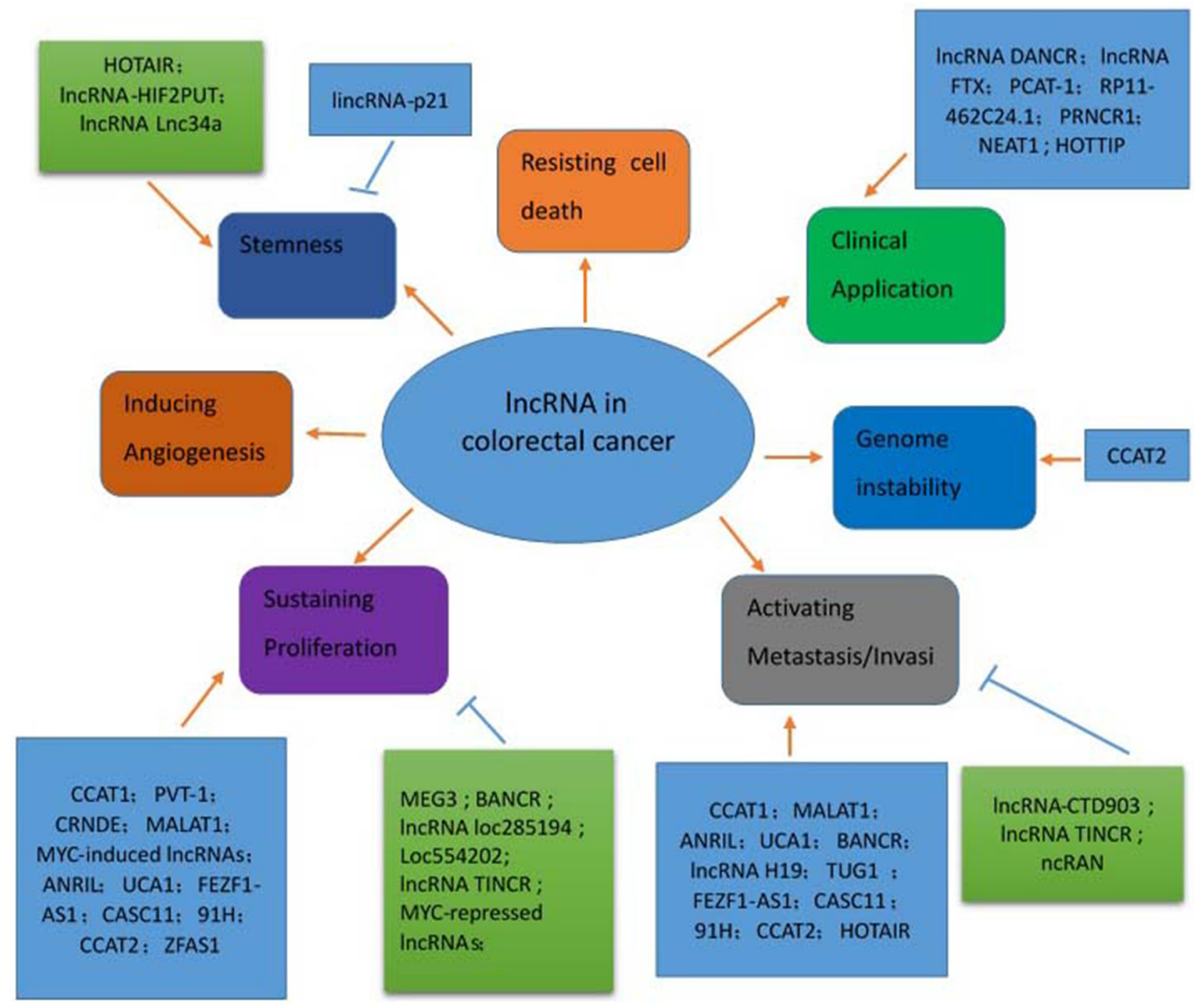

Figure 1: The functions of IncRNA in colorectal cancer pathogenesis. LncRNAs have multiple functions in the context of colorectal cancer, including increasing proliferation, angiogenesis, metastasis, invasion, apoptosis, stemness, and genomic instability. Red arrows indicate promoted signaling pathways. Blue arrows indicate inhibited signaling pathways. Some LncRNAs have multiple functions (for example, CCAT2 promotes proliferation, metastasis, and genomic instability). Abbreviations: CCAT2: colon cancer-associated transcript 2; CCAT1: LncRNA colon cancer-associated transcript 1; BANCR: BRAF-activated lncRNA; TUG1: Taurine up-regulated gene 1; FEZF1-AS1: long noncoding RNA FEZF1 antisense RNA1; CASC11: cancer susceptibility candidate 11; CRNDE: Colorectal Neoplasia Differentially Expressed; UCA1:urothelial carcinoma-associated 1 ;MEG3: maternally expressed gene 3; MALAT1: metastasis associated lung adenocarcinoma transcript 1; ANRIL: Antisense noncoding RNA in the INK4 locus; HOTAIR: Hox transcript antisense intergenic RNA; HOTTIP: 'HOXA transcript at the distal tip' 
Table 1: A summary of IncRNAs involved in colorectal cancer development and progression

\begin{tabular}{ccc}
\hline LncRNA & $\begin{array}{c}\text { In colorectal } \\
\text { cancer, its } \\
\text { expressions is: }\end{array}$ & Functions \\
\hline
\end{tabular}

Colon Cancer Associated

Transcript 1 (CCAT1)

Plasmacytoma variant

translocation 1(PVT-1)

Colorectal Neoplasia

Differentially Expressed

(CRNDE)

Metastasis Associated Lung

Adenocarcinoma Transcript

1 (MALAT1)

ZNFX1 antisense RNA 1

(ZFAS1)

\begin{abstract}
MYC-induced lncRNAs
(MYCLo-1, MYCLo-2, MYCLo-3)
\end{abstract}

MYC-repressed lncRNAs

(MYCLo-4, MYCLo-5, MYCLo-6)

Antisense noncoding RNA in the INK4 locus (ANRIL)

urothelial carcinomaassociated 1 (UCA1)

BRAF-activated lncRNA (BANCR)

Downregulated

Maternally expressed gene 3

(MEG3)

LncRNA loc285194

Upregulated

Upregulated

Upregulated

Upregulated

Downregulated

Upregulated

Upregulated

Downregulated

Upregulated
Upregulated

Promotes cellular proliferation, migration, and invasion.

Promotes proliferation and invasion. Knockdown of PVT-1 promotes apoptosis in colorectal cancer cell lines by activating the TGF- $\beta$ signaling pathway.

Promotes colon cancer cell proliferation.

Promotes cellular proliferation, migration, and invasion via 1) binding to SFPQ and releasing oncogene PTBP2 from SFPQ/PTBP2 complex 2) increasing expression of AKAP-9 via promoting SRPK1-catalyzed SRSF1 phosphorylation in colorectal cancer cells.

Silencing of ZFAS1 decreases CRC cell proliferation via G1-arrest of the cell cycle and decreasing CRC tumorigenicity. ZFAS1 acts as an oncogene in $\mathrm{CRC}$ via 1) destabilization of $\mathrm{p} 53$;

2) interaction with CDK1/cyclin B1 complex leading to cell cycle progression and suppression of apoptosis.

Promotes MYC-modulated cell proliferation. MYCLo-1/-2 promote G1/S transition. MYCLo-3 decreases cellular time spent in the $\mathrm{S}$ and $\mathrm{G} 2$ phases.

Inhibits MYC-enhanced cell proliferation. MYCLo-4/-6 increase G2 arrest. MYCLo-5 decreases cellular populations in the $\mathrm{S}$ phase.

Promotes proliferation in a $\mathrm{p} 15 / \mathrm{p} 16-\mathrm{pRB}$ pathwayindependent manner, and promotes cell invasion and migration.

Activates proliferation, suppresses apoptosis and cell cycle progression of CRC cells. UCA1 induces $\mathrm{CRC}$ migration and invasion and predicts poor prognosis.

Inhibits the proliferation in part through upregulation of p21, induces the epithelialmesenchymal transition (EMT) through an MEK/ extracellular signal-regulated kinase-dependent mechanism.

Inhibits CRC cell proliferation and is an independent predictor for overall survival.

Downregulated Suppresses tumor cell growth due to specific suppression of miR-211. Low expression of LOC285194 is associated with larger tumor size, higher tumor stage, more distant metastasis and poorer disease free survival.
$[8,9,10]$

[6]

$[11,12,13]$

$[14,15,16,17]$

(Continued) 


\begin{tabular}{|c|c|c|c|}
\hline LncRNA & $\begin{array}{l}\text { In colorectal } \\
\text { cancer, its } \\
\text { expressions is: }\end{array}$ & Functions & Reference \\
\hline Loc554202 & Downregulated & $\begin{array}{c}\text { Suppresses the cell proliferation, induces } \\
\text { apoptosis, partly through activating specific } \\
\text { caspase cleavage cascades, and inhibits CRC } \\
\text { tumorigenesis. }\end{array}$ & [32] \\
\hline LncRNA H19 & Upregulated & Promotes EMT in CRC. & [34] \\
\hline $\begin{array}{l}\text { Hox transcript antisense } \\
\text { intergenic RNA (HOTAIR) }\end{array}$ & Upregulated & $\begin{array}{l}\text { Indicates poorer prognosis, promotes migration and } \\
\text { invasion, enhances CSC properties, promotes cellular } \\
\text { proliferation, decreases the expression of E-cadherin } \\
\text { and increases expression of vimentin and MMP9. }\end{array}$ & {$[36,49]$} \\
\hline $\begin{array}{l}\text { HOTTIP('HOXA transcript } \\
\text { at the distal tip') }\end{array}$ & Upregulated & Predicts unfavorable prognosis for CRC patients. & [37] \\
\hline $\begin{array}{l}\text { Taurine up-regulated gene } 1 \\
\text { (TUG1) }\end{array}$ & Upregulated & $\begin{array}{l}\text { Increases the invasive and metastatic ability of } \\
\text { CRC cells through activating EMT process and } \\
\text { TUG1 overexpression indicates poor survival rates } \\
\text { and a higher risk for cancer metastasis. }\end{array}$ & [38] \\
\hline $\begin{array}{l}\text { FEZF1 antisense RNA1 } \\
\text { (FEZF1-AS1) }\end{array}$ & Upregulated & $\begin{array}{l}\text { Promotes migration and proliferation through } \\
\text { activating the G1-S checkpoint }\end{array}$ & [39] \\
\hline $\begin{array}{l}\text { Cancer susceptibility } \\
\text { candidate } 11 \text { (CASC11) }\end{array}$ & Upregulated & $\begin{array}{c}\text { Promotes CRC cell proliferation and metastasis by } \\
\text { activation of WNT/ } \beta \text {-catenin signaling. }\end{array}$ & [40] \\
\hline $91 \mathrm{H}$ & Upregulated & $\begin{array}{l}\text { Promotes the proliferation, migration, and } \\
\text { invasiveness of CRC cells. }\end{array}$ & [41] \\
\hline LncRNA-CTD903 & Downregulated & $\begin{array}{l}\text { Predicts favorable prognosis in CRC patients } \\
\text { and suppresses invasion and migration through } \\
\text { repressing Wnt/ } \beta \text {-catenin signaling. }\end{array}$ & [42] \\
\hline LncRNA TINCR & Downregulated & $\begin{array}{l}\text { Suppresses CRC proliferation and metastasis by } \\
\text { accelerating the cleavage of EpCAM and releases } \\
\text { EpICD via activating WNT/ } \beta \text { - catenin pathway. }\end{array}$ & [43] \\
\hline ncRAN & Downregulated & $\begin{array}{l}\text { Inhibits in vitro migration and invasion of CRC } \\
\text { cells and predicts CRC patient outcome. }\end{array}$ & [44] \\
\hline $\begin{array}{l}\text { Colon cancer-associated } \\
\text { transcript } 2 \text { (CCAT2) }\end{array}$ & Upregulated & $\begin{array}{c}\text { Promotes tumor growth, metastasis, and } \\
\text { chromosomal instability. It functions as a WNT } \\
\text { downstream target. }\end{array}$ & [46] \\
\hline LncRNA-HIF2PUT & Upregulated & $\begin{array}{c}\text { Promotes the HIF- } 2 \alpha \text { expression and the CSC } \\
\text { properties. }\end{array}$ & [48] \\
\hline $\begin{array}{l}\text { Lnc34a(locus mainly in the } \\
\text { nucleus) }\end{array}$ & Upregulated & $\begin{array}{c}\text { Enhances CSC self-renewal and tumorigenesis and } \\
\text { suppresses miR-34a expression. }\end{array}$ & [50] \\
\hline LincRNA-p21 & Downregulated & $\begin{array}{l}\text { Attenuates the viability, self-renewal, and } \\
\text { glycolysis of CSCs. }\end{array}$ & [51] \\
\hline LncRNA DANCR & Upregulated & $\begin{array}{c}\text { Serves as a potential prognosis predictor for CRC } \\
\text { prognosis, associates with TNM stage, histologic } \\
\text { grade, and lymph node metastasis, and predicts } \\
\text { shorter overall survival and disease-free survival } \\
\text { time. }\end{array}$ & [52] \\
\hline
\end{tabular}

(Continued) 


\begin{tabular}{|c|c|c|c|}
\hline LncRNA & $\begin{array}{l}\text { In colorectal } \\
\text { cancer, its } \\
\text { expressions is: }\end{array}$ & Functions & Reference \\
\hline LncRNA FTX & Upregulated & $\begin{array}{l}\text { Serves as an independent prognostic factor for } \\
\text { CRC patients and is associated with differentiation } \\
\text { grade, lymph vascular invasion, and clinical stage; } \\
\text { indicates poorer overall survival. }\end{array}$ & [53] \\
\hline $\begin{array}{l}\text { Prostate cancer associated } \\
\text { transcript } 1 \text { (PCAT-1) }\end{array}$ & Upregulated & $\begin{array}{c}\text { Functions as an independent prognostic factor } \\
\text { for CRC patient outcome and implicates poorer } \\
\text { overall survival. }\end{array}$ & {$[54,55]$} \\
\hline RP11-462C24.1 & Downregulated & $\begin{array}{l}\text { Serves as a prognosis indicator for CRC patients. } \\
\text { Its down-regulation indicates increased distant } \\
\text { metastasis and a poor disease-free survival. }\end{array}$ & [56] \\
\hline PRNCR1 & Upregulated & Serves as a sensitive diagnostic biomarker of CRC. & [57] \\
\hline NEAT1 & Upregulated & $\begin{array}{c}\text { Functions as s diagnostic and prognostic } \\
\text { biomarker of overall survival in CRC, associates } \\
\text { with tumor differentiation, invasion, metastasis } \\
\text { and TNM stage and predicts shorter disease-free } \\
\text { survival time and overall survival time. }\end{array}$ & {$[58,59]$} \\
\hline
\end{tabular}

Table 2: LncRNAs involved in sustained proliferation of CRC

\begin{tabular}{lccc}
\hline LncRNA & $\begin{array}{c}\text { In colorectal cancer, its } \\
\text { expressions is: }\end{array}$ & Functions & Reference \\
\hline
\end{tabular}

(1)

LncRNA

CCAT1

PVT-1

CRNDE

MALAT1

ZFAS1
Upregulated

Upregulated

Upregulated

Expression

Upregulated

Upregulated

Upreguted
Functions

Promotes colon cancer cell proliferation.

Promote proliferation and invasion;

Knockdown of PVT-1 promotes apoptosis in colorectal cancer cell lines

by activating the TGF- $\beta$ signalling pathway.

Promotes colon cancer cell proliferation.

Promotes cellular proliferation, migration, and invasion via 1) binding

to SFPQ and releasing oncogene

PTBP2 from SFPQ/PTBP2 complex 2) increasing expression of AKAP-9 via promoting SRPK1-catalyzed SRSF1 phosphorylation in colorectal cancer cells.

Silencing of ZFAS1 decreases CRC cell proliferation via G1-arrest of the cell cycle and decreasing CRC tumorigenicity. ZFAS1 acts as an oncogene in CRC via 1) destabilization of $\mathrm{p} 53 ; 2$ ) interaction with CDK1/ cyclin B1 complex leading to cell cycle progression and suppression of apoptosis.
Reference

[6]

$[8,9,10]$

$[11,12,13]$

$[14,15,16,17]$

(Continued) 


\begin{tabular}{|c|c|c|c|}
\hline LncRNA & $\begin{array}{l}\text { In colorectal cancer, its } \\
\text { expressions is: }\end{array}$ & Functions & Reference \\
\hline $\begin{array}{l}\text { MYC-induced } \\
\text { lncRNAs } \\
\text { (MYCLo-1, } \\
\text { MYCLo-2, } \\
\text { MYCLo-3) }\end{array}$ & Upregulated & $\begin{array}{c}\text { Promotes MYC-modulated cell } \\
\text { proliferation. MYCLo-1/-2 promote } \\
\text { G1/S transition. MYCLo-3 decreases } \\
\text { cellular time spent in the S and G2 } \\
\text { phases }\end{array}$ & [18] \\
\hline $\begin{array}{l}\text { MYC-repressed } \\
\text { lncRNAs } \\
\text { (MYCLo-4, } \\
\text { MYCLo-5, } \\
\text { MYCLo-6) }\end{array}$ & Downregulated & $\begin{array}{l}\text { Inhibits MYC-enhanced cell } \\
\text { proliferation. MYCLo-4/-6 increase } \\
\text { G2 arrest. MYCLo-5 decreases cellular } \\
\text { populations in the S phase. }\end{array}$ & [19] \\
\hline ANRIL & Upregulated & $\begin{array}{l}\text { Promotes proliferation in a p15/p16- } \\
\text { pRB pathway-independent manner. }\end{array}$ & [20] \\
\hline UCA1 & Upregulated & $\begin{array}{c}\text { Activates proliferation, suppresses } \\
\text { apoptosis and cell cycle progression of } \\
\text { CRC cells. }\end{array}$ & {$[21,22,23]$} \\
\hline BANCR & Downregulated & $\begin{array}{c}\text { Inhibits the proliferation in part through } \\
\text { upregulation of } \mathrm{p} 21\end{array}$ & [24] \\
\hline $\begin{array}{l}\text { Maternally } \\
\text { expressed gene } 3 \\
\text { (MEG3) }\end{array}$ & Downregulated & $\begin{array}{l}\text { Inhibits CRC cell proliferation and } \\
\text { serves as an independent predictor for } \\
\text { overall survival. }\end{array}$ & [25] \\
\hline $\begin{array}{l}\text { LncRNA } \\
\text { loc285194 }\end{array}$ & Downregulated & $\begin{array}{l}\text { Suppresses tumor cell growth due to } \\
\text { specific suppression of miR-211. Low } \\
\text { expression of LOC285194 shows larger } \\
\text { tumor size, higher tumor stage, more } \\
\text { distant metastasis and poorer disease } \\
\text { free survival. }\end{array}$ & {$[26,27,28]$} \\
\hline Loc554202 & Downregulated & $\begin{array}{c}\text { Inhibits the cell proliferation and } \\
\text { induces apoptosis, partly through } \\
\text { activating specific caspase cleavage } \\
\text { cascades. }\end{array}$ & [32] \\
\hline $\begin{array}{l}\text { Long noncoding } \\
\text { RNA FEZF1 } \\
\text { antisense RNA1 } \\
\text { (FEZF1-AS1) }\end{array}$ & Upregulated & $\begin{array}{l}\text { Promotes proliferation through } \\
\text { activating the G1-S checkpoint. }\end{array}$ & [39] \\
\hline
\end{tabular}

copy-number. CRC cells transfected with PVT-1 specific siRNA exhibited significant proliferative and invasive capability loss [7], supporting PVT-1 as a potential carcinogenic lncRNA in CRC. Another oncogenic lncRNA regulating CRC proliferation is Colorectal Neoplasia Differentially Expressed (CRNDE) [8], which is located on chromosome 16 of the human genome. It shares a bidirectional promoter with iroquois homeobox 5 (IRX5), which is adjacent at the opposite strand. The expression of CRNDE is tissue-specific, and follows a temporal pattern. Rarely is CRNDE observed in adult colorectal mucosa, liver, and white blood cells, and increased CRNDE expression occurs in the testis, breast, and skin [9]. Additionally, CRNDE expression is significantly increased in several neoplastic diseases, including colorectal cancer. There are two existing CRNDE transcripts: cytoplasmic (fully spliced and free of intron sequences) and nuclear (the intron sequences) transcripts. Insulin, IGF1, and IGF2 do not increase or decrease cytoplasmic CRNDE transcripts, but decrease nuclear CRNDE transcripts via both the PI3K/Akt/mTOR and Raf/MAPK pathways. Knockdown of gVC-In4, a highly-conserved region of CRNDE, affects insulin signaling responses, as well as many genes associated with glucose/lipid metabolism. Several other insulin-regulated genes are affected by gVC-In4 knockdown as well. GLUT4, an insulinregulated glucose transporter, translocates to the plasma membrane, allowing intracellular glucose transport. 
CRNDE increases GLUT4 and MLXIPL transcription. gVC-In4 knockdown decreases glucose intake, thereby causing less lactate secretion. The increased expression of CRNDE nuclear transcripts promotes glucose metabolism, lactate secretion, and lipid synthesis in CRC cells. CRNDE nuclear transcripts influence upstream insulin/IGF signaling pathways. Thus CRNDE nuclear transcripts, which are inhibited by insulin, IGF1, and IGF2 via PI3K/Akt/mTOR and Raf/MAPK pathways, promote central metabolism [10]. Another well known lncRNA overexpressed in CRC is the human metastasis associated lung adenocarcinoma transcript 1 (MALAT1) [11]. Xu et al first reported that one fragment (6918 nt$8441 \mathrm{nt}$, located at the 3' end) of MALAT-1 is influential in the biological processes of cell proliferation, migration, and invasion [11]. Several mechanisms connect MALAT1 to CRC cellular proliferation. It has been reported that MALAT1 overexpression enhances cell proliferation and migration in vitro, and promotes tumor growth and metastasis in nude mice, due to tumor suppressor gene SFPQ and proto-oncogene PTBP2. MALAT1 binds SFPQ, releasing PTBP2 from the SFPQ/PTBP2 complex. In turn, increased levels of SFPQ-detached PTBP2 promote cell proliferation and migration. In this sense, SFPQ mediates the regulatory effects of MALAT1 [12]. Furthermore, MALAT1 interacts with both SRPK1 and SRSF1. MALAT1 increases AKAP-9 expression by promoting SRPK1-catalyzed SRSF1 phosphorylation. After MALAT1 knockdown, overexpression of SRPK1 restored SRSF1 phosphorylation and AKAP-9 expression, promoting cell proliferation, invasion, and migration in vitro. Conversely, SRPK1 knockdown after overexpression of MALAT1 in a CRC cell line reduced SRSF1 phosphorylation and AKAP-9 expression, and inhibited cell proliferation, invasion, and migration in vitro. These findings suggest MALAT1 increases AKAP9 expression by promoting SRPK1-catalyzed SRSF1 phosphorylation in CRC cells [13].

Thorenoor et al recently profiled expression of disease-associated lncRNAs in CRC tumor tissues and identified ZFAS1 (zinc finger antisense 1), previously known to be a tumor suppressor gene in human breast cancer $[14,15]$ and oncogene in hepatocellular carcinoma [16], to be overexpressed in CRC tissue. ZFAS1 silencing reduced CRC cell proliferation through G1-arrest of cell cycle, and also tumorigenicity of CRC cells. Via RIP (RNA immunoprecitation) analysis, the authors identified Cyclin-dependent kinase 1 (CDK1) as an interacting partner of ZFAS1. Through bioinformatics analysis, the authors found that ZFAS1 could sponge miR-590-3p, which targets CDK1. The authors further demonstrated ZFAS1 activates CDK1 and cyclin B1. When ZFAS1 is silenced, cyclin B1 is decreased. ZFAS1 silencing activates P53 and PARP cleavage, increasing CRC cell apoptosis. Taken together, ZFAS1 advances cell cycle progression and inhibits apoptosis, via activation of P53 and CDK1/cyclin B1 complex, thus critical for CRC cell viability, cell cycle distribution, apoptosis, and colony formation [17]. Kim recently identified MYCLos as a key molecule in CRC cell cycle regulation and tumorigenesis, by influencing MYC target genes such as CDKN1A (p21) and CDKN2B (p15) [18]. RNA binding proteins HuR and hnRNPK are involved in the function of MYCLos, by respectively interacting with MYCLo-1 and MYCLo-2. Knockdown of MYCLo-2, differentially expressed in $\mathrm{CRC}$, inhibits cancer transformation and tumorigenesis [18]. The same research group later characterized another three MYC-repressed lncRNAs named MYCLo-4, -5, and -6 . The MYC-repressed MYCLos were proved to suppress cell cycle progression, and therefore inhibiting cell proliferation. Through screening all cell cycle-related genes affected by MYC and MYC-repressed MYCLos, the MYC-repressed gene GADD45A has been identified to be a target gene of MYCLo-4 and MYCLo-6 [19].

ANRIL is a lncRNA transcribed from the INK4 locus, and encodes three tumor suppressor genes (p15, p16, and ARF). ANRIL represses p15 and p16, which positively regulate the $\mathrm{pRB}$ pathway, repressing senescence of normal human fibroblasts [20]. However, the role of ANRIL in cancer cell proliferation is not well understood. Naemura et al reported ANRIL increased proliferation of colorectal cancer HCT116 cells in twoand three-dimensional cultures. Silencing ANRIL by siRNA and retroviral-produced shRNA decreased HCT116 cell proliferation in both two- and three-dimensional cultures. HCT116 cells depleted of ANRIL were arrested in the S phase of the cell cycle. Notably, silencing ANRIL did not activate expression of the INK4 locus. These observations suggest ANRIL increases proliferation of HCT116 cells in two- and three-dimensional cultures via p15/p16-pRB [20].

The IncRNA urothelial carcinoma-associated 1 (UCA1) is significantly overexpressed in most tumor tissues and cancer cells. Han et al demonstrated UCA1 levels were markedly increased in CRC tissues and cells compared to control, and the level of UCA1 expression was positively correlated with tumor size, poor histological differentiation, and increased tumor depth. Increased UCA1 expression carried significantly poorer prognosis and overexpression of UCA 1 increases proliferation, and decreases apoptosis and cell cycle progression of CRC cells [21]. Ni et al further demonstrated that increased UCA1 expression was positively correlated to lymph node metastasis, distant metastasis, and tumor stage. Survival analysis revealed correlation between increased UCA1 expression and poor prognosis. Moreover, multivariate analysis identified UCA1 overexpression as an independent predictor for CRC. UCA1 knockdown significantly decreased CRC proliferation and metastasis. Flow cytometry assays demonstrated UCA1 silencing induced G0/G1 growth arrest and apoptosis of CRC cells. To further investigate the regulatory mechanisms 
of UCA1, the authors identified that Ets-2 bound to the UCA1 core promoter using luciferase assays [22]. This observation suggested that UCA1 might be an important prognostic predictor in $\mathrm{CRC}$ and might be considered as a potential target for CRC diagnosis and gene therapy. More recently, Bian et al reported UCA1 sponged endogenous miR-204-5p, thereby inhibiting its activity in CRC, and identified CREB1 as a new target of miR-204-5p. The protein levels of CREB1 were significantly increased in CRCs, positively correlated with UCA1 expression, and negatively associated with survival. Taken together, Bian et al's work demonstrated existence of a UCA1-miR-2045p-CREB1/BCL2/RAB22A regulatory network in CRC, supporting UCA1 and CREB1 as potential new oncogenes and prognostic factors for CRC [23].

LncRNAs may serve as tumor suppressors inhibiting CRC cellular proliferation. BRAF-activated non-coding RNA (BANCR) was first discovered during an RNAseq screen for transcripts influenced by the expression of the oncogene BRAFV600E. Shi et al demonstrated significantly decreased expression of BANCR in three colorectal cancer cell lines. Suppression of BANCR increases proliferation of colorectal cancer cells, partly via downregulation of p21 [24]. Maternally expressed gene 3 (MEG3) is another lncRNA that functions as a $\mathrm{CRC}$ proliferative suppressor. Yin et al reported decreased MEG3 levels correlated positively with low histological grade, increased tumor invasion, and advanced tumor node metastatic (TNM) stage CRC disease. Multivariate analyses revealed that MEG3 expression served as an independent predictor for overall survival. Further experiments demonstrated MEG3 overexpression significantly inhibited CRC cell proliferation both in vitro and in vivo [25].

Two lncRNAs have recently been identified as CRC proliferation inhibitors. Pasic et al first reported in 2010 lncRNA loc285194 to be within a tumor suppressor unit in osteosarcoma, and suppressed tumor cell growth [26]. Another research group demonstrated LOC285194 to be decreased in tumor tissues and colorectal cancer cell lines compared to normal intestinal mucous cell lines. Additionally, low levels of LOC285194 were correlated with larger tumor size, increased tumor stage, more distant metastasis, and decreased disease-free survival [27]. Liu et al demonstrated loc285194 is a p53 transcription target, and ectopic expression of loc285194 inhibits tumor cell growth both in vitro and in vivo. Through deletion analysis, Liu et al identified an active region responsible for tumor cell growth inhibition within exon 4, which harbors two miR-211 binding sites. This loc285194-mediated growth inhibition is partially due to specific suppression of miR211 [28]. The second newly discovered CRC inhibitor lncRNA is loc554202. Loc554202 is a 2166-bp transcript on human chromosome 9p21.3, previously shown to be dysregulated in breast and lung cancer [29-31]. Ding et al reported expression of Loc554202 was significantly inhibited in CRC cell lines compared to normal human intestinal epithelial cell lines. Decreased loc554202 expression was associated with advanced pathologic stage and a larger tumor size. Moreover, loc554202 expression decreased cellular proliferation, induced apoptosis in vitro, and hindered tumorigenesis in vivo, partly via specific caspase cleavage cascade activation [32].

\section{ACTIVATING METASTASIS/INVASION PROGRAM}

Although primary CRC can be treated by surgical resection, patient survival deteriorates once metastasis to vital organs (such as the liver or lungs) has occurred. Primary CRC develops progressively through accumulation of genetic mutations (e.g., APC, KRAS, p53, SMAD4, and PTEN) and epigenetic silencing of tumor suppressor genes. Mounting evidence suggests lncRNAs influence the invasive and metastatic potential of CRC (Figure 2 and Table 3). For instance, Guo et al. determined BANCR is overexpressed in CRC tissues, correlating with increased lymph node metastasis and tumor stage. While ectopic BANCR expression increased migration of human CRC Caco-2 cells, BANCR knockdown inhibited in vitro HCT116 cell migration [33], via induction of the epithelial-mesenchymal transition (EMT) through a MEK/extracellular signal-regulated kinase-dependent mechanism. These results suggest BANCR is essential for CRC metastasis, with great potential therapeutic value against CRC progression.

The IncRNA H19, a known oncogene in various cancer types, tumorigenesis and cancer progression. Liang et al recently characterized $\mathrm{H} 19$ as a novel regulator of epithelial-to-mesenchymal transition (EMT) in CRC. H19 is highly expressed in mesenchymal-like cancer cells and primary CRC tissues. Stable H19 expression promotes EMT progression and accelerates in vivo and in vitro tumor growth. Bioinformatics in combination with RIP analysis revealed $\mathrm{H} 19$ functions as a competing endogenous RNA (ceRNA) for miR-138 and miR200a, antagonizing their function, and activating their endogenous targets Vimentin, ZEB1, and ZEB2, all key marker genes of mesenchymal cells. In summary, lncRNA H19 is involved in EMT program as a competing endogenous RNA, ultimately contributing to CRC progression [34].

HOTAIR (the Hox transcript antisense intergenic RNA), is a lncRNA expressed from the developmental HOXC locus located on chromosome 12q13.13. Kogo et al reported HOTAIR expression levels were higher in cancerous tissues than in noncancerous tissues, and increased HOTAIR expression correlated positively with the liver metastasis. Moreover, patients expressing increased HOTAIR levels had poor prognosis. In a subset of 32 CRC specimens, gene set enrichment analysis using cDNA array data revealed a close correlation 
between expression of HOTAIR and members of the PRC2 complex (SUZ12, EZH2, and H3K27me3) [35]. $\mathrm{Wu}$ et al more recently demonstrated HOTAIR was associated with epithelial-mesenchymal transition in CRC, reporting HOTAIR depletion increased the expression of E-cadherin while concomitantly decreasing expression of vimentin and MMP9 [36]. Upregulation of HOTAIR might be a critical element contributing to CRC metastatic progression. LncRNA taurine up-regulated gene 1 (TUG1) has been reported to be correlated with cancer progression. Sun et al specifically analyzed TUG1 in the context of CRC, and demonstrated TUG1 expression was significantly increased in CRC cell lines, suggesting TUG1 downregulation may be a negative prognostic factor for CRC patients. TUG1 may increase the invasive and metastatic ability of CRC cells, at least in part through influencing the EMT process [38].

LncRNA FEZF1 antisense RNA1 (FEZF1-AS1) was recently corroborated to be significantly oveexpressed in human primary $\mathrm{CRC}$, and is associated with CRC metastasis and poor prognosis. Moreover, suppression of FEZF1-AS1 expression significantly inhibited CRC cell proliferation, migration and invasiveness, suppressed S-phase entry in vitro, and repressed tumor growth and metastasis in vivo. FEZF1-AS1 overexpression increased malignant aspects of CRC cells. Dysregulation of FEZF1-
AS1 therefore participates in $\mathrm{CRC}$ tumorigenesis and progression [39]. Moreover, The overexpression of FEZF1-AS1 leads to significant cells reduction at G0/G1phase and increase in S-phase. Conversely, knockdown of FEZF1-AS1 does just the opposite. FEZF1-AS1 induces CRC cell proliferation by activating the G1-S checkpoint [39].

Cancer susceptibility candidate 11 (CASC11) is overexpressed in CRC tissues and is positively associated with tumor size, serosal invasion, lymph metastasis, and tumor-node-metastasis (TNM) stage. CASC11 promotes CRC cell proliferation and metastasis in vitro and in vivo. CASC11 increases expression of heterogeneous ribonucleoprotein $\mathrm{K}$ (hnRNP-K) and $\beta$-catenin nuclear accumulation, activating $\mathrm{WNT} / \beta$-catenin signaling in CRC cells [40]. Additionally, c-Myc directly binds the promoter regions of CASC11, increasing promoter histone acetylation, augmenting CASC11 expression. CASC11 has potential as a diagnostic biomarker, and may be an effective therapeutic against CRC. In addition, located on the H19/IGF2 locus (119.329 kbs long), 91H (H19 antisense RNA) is a lncRNA which is overexpressed in $\mathrm{CRC}$ tissue and cell lines. $91 \mathrm{H}$ overexpression is correlated with increased metastasis and poor prognosis. Multivariate analysis demonstrates $91 \mathrm{H}$ expression is an independent prognostic and metastatic indicator of CRC.

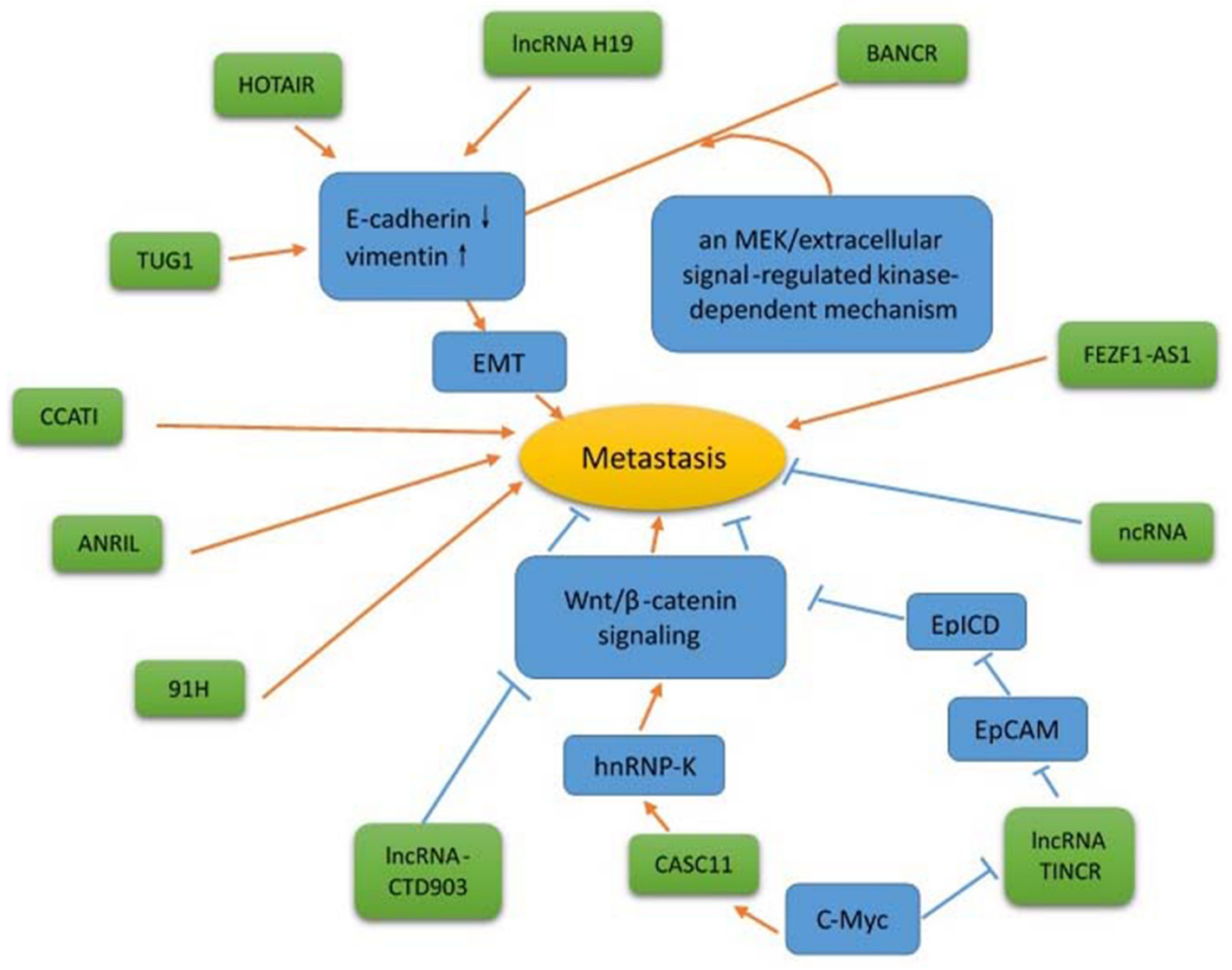

Figure 2: The regulation of metastasis by IncRNA. Red arrows indicate promoted signaling pathways; blue arrows indicate inhibited signaling pathways. Several lncRNAs (such as CCAT1, ANRIL, 91H, FEZF1-AS1, and ncRNA) have unknown mechanisms. 
Table 3: LncRNAs participate in metastasis/invasion-promoting programs of CRC

\begin{tabular}{|c|c|c|c|}
\hline LncRNA & $\begin{array}{l}\text { In colorectal cancer, its } \\
\text { expressions is: }\end{array}$ & Functions & Reference \\
\hline CCAT1 & Upregulated & $\begin{array}{c}\text { Promotes cell migration and } \\
\text { invasion. }\end{array}$ & {$[6]$} \\
\hline BANCR & Upregulated & $\begin{array}{l}\text { Induces EMT program through an } \\
\text { MEK/extracellular signal-regulated } \\
\text { kinase-dependent mechanism. }\end{array}$ & {$[33]$} \\
\hline LncRNA H19 & Upregulated & Promotes EMT in CRC. & {$[34]$} \\
\hline HOTAIR & Upregulated & $\begin{array}{l}\text { Promotes migration and invasion, } \\
\text { decreases expression of E-cadherin, } \\
\text { increases expression of vimentin } \\
\text { and MMP9 and associates with } \\
\text { poorer prognosis. }\end{array}$ & {$[36]$} \\
\hline TUG1 & Upregulated & $\begin{array}{l}\text { Increases the invasive and } \\
\text { metastatic ability of CRC cells } \\
\text { through activating EMT process }\end{array}$ & {$[38]$} \\
\hline FEZF1-AS1 & Upregulated & Promotes migration. & {$[39]$} \\
\hline CASC11 & Upregulated & $\begin{array}{l}\text { Promotes CRC cell metastasis, } \\
\text { dependent on activation of } \mathrm{WNT} / \beta \text { - } \\
\text { catenin signaling. }\end{array}$ & {$[40]$} \\
\hline $91 \mathrm{H}$ & Upregulated & $\begin{array}{l}\text { Promotes proliferation, migration, } \\
\text { and invasiveness of CRC cells. }\end{array}$ & {$[41]$} \\
\hline LncRNA-CTD903 & Downregulated & $\begin{array}{c}\text { Suppresses invasion and migration } \\
\text { through repressing Wnt/ } \beta \text {-catenin } \\
\text { signaling. }\end{array}$ & {$[42]$} \\
\hline LncRNA TINCR & Downregulated & $\begin{array}{c}\text { Suppresses CRC proliferation } \\
\text { and metastasis by accelerating the } \\
\text { cleavage of EpCAM and releasing } \\
\text { EpICD via activating WNT/ } \beta \text { - } \\
\text { catenin pathway. }\end{array}$ & {$[43]$} \\
\hline ncRAN & Downregulated & $\begin{array}{l}\text { Inhibits migration and invasion of } \\
\text { CRC cells. }\end{array}$ & {$[44]$} \\
\hline ANRIL & Upregulated & $\begin{array}{c}\text { Promotes cell invasion and } \\
\text { migration. }\end{array}$ & {$[61]$} \\
\hline
\end{tabular}

Moreover, knockdown of $91 \mathrm{H}$ inhibited the proliferation, migration, and invasiveness of CRC cells [41].

Several lncRNAs that suppress metastasis were recently discovered. IncRNA-CTD903 is an independent predictor of favorable prognosis in CRC patients. After knockdown of CTD903 in CRC cell lines, CRC cells were noted to exhibit EMT-like appearance, decreased adherence ability, and increased invasion and migration characteristics. Inhibition of CTD903 increased Wnt/ $\beta$ catenin activation, increased transcription factors Twist and Snail expression, increased mesenchymal marker Vimentin, and decreased epithelial marker ZO-1. LncRNA-CTD903 is therefore likely a suppressor of metastasis in $\mathrm{CRC}$ via $\mathrm{Wnt} / \beta$-catenin signaling repression
[42]. Another suppressor of CRC metastasis is TINCR, a $3.7 \mathrm{~kb}$ lncRNA. TINCR levels are negatively correlated with CRC progression, tumor growth, and metastasis (both in vivo and in vitro). During physiologic conditions, TINCR binds EpCAM. Loss of TINCR increases hydrolysis of EpCAM, increases release of EpICD, and activates the Wnt/ $\beta$-catenin pathway. c-Myc decreases TINCR expression via repression of sp1-transcriptive activity, establishing a positive feedback loop controlling c-Myc and TINCR expression. Loss of TINCR expression promotes proliferation and metastasis in CRC, and is therefore a potential cancer suppressor gene [43]. ncRNA (non-coding RNA expressed in aggressive neuroblastoma) has previously been demonstrated to be overexpressed and 
associated with poor prognosis in human neuroblastoma, as well as bladder cancer. However, ncRAN is significantly decreased in CRC tumor tissue and CRC cell lines. Moreover, expression of ncRAN is inhibited in poorly differentiated or undifferentiated CRC tumors, and in CRC tumors with liver metastases. Multivariate analysis demonstrates decreased ncRAN expression is an independent predictor of overall survival. Taken together, these data suggest ncRAN may be a biomarker for early CRC metastasis, a prognostic indicator, and a therapeutic target against CRC [44].

\section{GENOME INSTABILITY}

All organisms require faithful propagation of genetic material and transmission into progeny cells, and avoidance of mutation propagation that may lead to genomic instability and aberrant cellular activity. Various DNA insults may occur by extrinsic factors such as ultraviolet (UV) radiation, ionizing radiation (IR), and numerous genotoxic chemicals [45]. In cancer cells, the rates of mutation increase due to breakdown of the genomic maintenance machinery. Despite cancer cell adaptation to this increased mutation rate, there is inevitably genomic instability within tumors themselves. Unfortunately, few investigations have identified potential lncRNAs involved in this process in CRC (Table 4). Ling et al reported that colon cancer-associated transcript 2 (CCAT2), a novel lncRNA encompassing the rs6983267 SNP, was overexpressed in microsatellite-stable colorectal cancer and promoted tumor growth, metastasis, and chromosomal instability. MYC, miR-17-5p, and miR20a are upregulated by CCAT2 via TCF7L2-mediated transcriptional regulation. The interaction between CCAT2 and TCF7L2 enhances WNT signaling. As CCAT2 is a WNT downstream target, a feedback loop likely exists. SNP status affects CCAT2 expression, and allele G increases CCAT2 transcript production. CCAT2 activates WNT signaling by enhancing TCF7L2 transcriptional activity to increase MYC expression. CCAT2 transcription increases WNT target gene expression by binding TCF7L2 and modulating its transcriptional activity. CCAT2 likely promotes chromosomal instability and tumor growth by activating WNT signaling and increasing MYC expression via activation of CDC25A, miR-17-5p, and miR-20a) [46].

\section{STEMNESS}

CRC has been recently identified to encompass a subset of cells with stem/progenitor cell features known as cancer stem cells (CSCs), which could lead to advanced tumors and a poor prognosis [47]. Because CSCs contribute to tumor-initiating potential, invasion, metastasis, resistance to traditional therapies, and eventual relapse, the CSC model explains clinical events previously a mystery, including therapy resistance, minimal residual disease, and tumor recurrence. However, the molecular hallmarks of CSCs in colorectal cancer remain unelucidated. While lncRNAs have been identified to be intimiately involved with various malignancies, their role in stemness maintenance in CRC remain the subject of intense study (Table 5).

The IncRNA "IncRNA-HIF2PUT" is a promoter upstream transcript of hypoxia-inducible factor- $2 \alpha$ (HIF-2 $\alpha$ ) in CRC. The function of HIF-2 $\alpha$ is closely connected with "stem cell-like" properties, and the function of promoter upstream transcripts (PROMPTs) is often associated with the adjacent protein-coding transcripts. IncRNA-HIF2PUT expression is correlated with HIF-2 $\alpha$ levels in CRC tissues; knockdown of lncRNA-HIF2PUT blocked HIF-2 $\alpha$ expression, and inhibited CSC properties in CRC cell lines. Knockdown of LncRNA-HIF2PUT via siRNA decreased expression of stemness genes, impaired colony formation, decreased spheroid formation ability, retarded migration, and decreased invasiveness [48]. The well-known lncRNA HOTAIR also participates in stemness maintenance in CRC. Dou et al demonstrated CD133(+)-shHOTAIR exhibited decreased cellular proliferation, migration, invasion, colony-forming properties of in vitro CRC cells, as well as decreased Vimentin expression with increased E-cadherin expression. Down-regulation of HOTAIR expression in CD133(+) CSCs markedly decreased tumor growth and lung metastasis in xenograft nude mice [49]. Therefore, HOTAIR may be a potential therapeutic target against CRC CSCs. In addition, the lncRNA Lnc34a is abundant in the CSCs of CRC, and initiates asymmetric division by directly targeting miR-34a, disrupting spatial balance. Lnc34a recruits Dnmt3a via PHB2 and HDAC1, methylating and deacetylating the miR-34a promoter simultaneously, epigenetically silencing miR$34 \mathrm{a}$ expression independent of its upstream regulator, p53. Lnc34a levels increase CRC CSC self-renewal and CRC growth in xenograft models. Moreover, lnc34a is overexpressed in late-stage CRCs, causing epigenetic miR-34a silencing and CRC proliferation [50]. Wang et al recently identified lincRNA-p21 (large intergenic noncoding RNA p21) is a potent suppressor of the stem-like traits of CSCs purified from both primary CRC tissues and cell lines. LincRNA-p21 inhibited $\beta$-catenin signaling, thereby decreasing viability, self-renewal, and glycolysis of CSCs in vitro. Administration of Ad-lnc-p21-MRE significantly decreased the self-renewal potential and tumorigenicity of CSCs in nude mice [51]. In this sense, lincRNA-p21 might be promising therapeutic against CSCs in CRC.

\section{CLINICAL APPLICATION}

LncRNAs emerge from a previously overlooked region of the genome, as a novel source of potentially useful biomarkers characterizing disease progression, 
Table 4: Genome instability-related IncRNAs

\begin{tabular}{lcccc}
\hline LncRNA & $\begin{array}{c}\text { In colorectal cancer, its } \\
\text { expressions is: }\end{array}$ & Functions & Reference \\
\hline CCAT2 & Upregulated & Increases chromosomal instability. & {$[46]$} \\
\hline
\end{tabular}

Table 5: LncRNAs associated with stemness mantenance in CRC

\begin{tabular}{|c|c|c|c|}
\hline IncRNA & $\begin{array}{l}\text { In colorectal cancer, its } \\
\text { expressions is: }\end{array}$ & Functions & Reference \\
\hline LncRNA-HIF2PUT & Upregulated & $\begin{array}{l}\text { Enhances the HIF- } 2 \alpha \text { expression } \\
\text { and promotes CSC properties. }\end{array}$ & {$[48]$} \\
\hline LncRNA HOTAIR & Upregulated & $\begin{array}{l}\text { Promotes CSC properties, increases } \\
\text { cellular proliferation, migration, } \\
\text { invasion, colony-forming. }\end{array}$ & [49] \\
\hline $\begin{array}{l}\text { Lnc } 34 a(\text { locus mainly in the } \\
\text { nucleus) }\end{array}$ & Upregulated & $\begin{array}{c}\text { Enhances CSC self-renewal and } \\
\text { tumorigenesis and suppresses miR- } \\
\text { 34a expression. }\end{array}$ & {$[50]$} \\
\hline LincRNA-p21 & Downregulated & $\begin{array}{l}\text { Attenuates the viability, self- } \\
\text { renewal, and glycolysis of CSCs. }\end{array}$ & {$[51]$} \\
\hline
\end{tabular}

recurrence, and prognosis. The fact lncRNA expression levels are typically markedly increased or decreased depending upon disease state makes them ideal for useful clinical application. Most importantly, as we discover the mechanisms of their involvement in $\mathrm{CRC}$, their applicability as therapeutics against CRC may be determined (Table 6).

LncRNAs have been intensively investigated for their role in predicting $\mathrm{CRC}$ prognosis. Liu et al reported that lncRNA DANCR expression was significantly increased in CRC tissues compared to adjacent normal tissues. Increased lncRNA DANCR expression was negatively correlated with TNM stage, histologic grade, and lymph node metastasis. Moreover, increased lncRNA DANCR expression was associated with decreased overall and disease-free survival for CRC patients [52]. Therefore, lncRNA DANCR expression holds potential as a prognosis predictor for CRC. FTX is another lncRNA with prognostic potential in CRC. FTX was significantly overexpressed in CRC tissues. Decreased FTX expression is associated with decreased differentiation grade, lymphatic vascular invasion, and clinical stage. Further multivariate analyses revealed that increased FTX levels serves as an independent prognostic factor for CRC patient survival [53].

LncRNA PCAT-1 (prostate cancer-associated ncRNA transcripts 1) is involved with human prostate cancer progression [54]. Ge et al demonstrated markedly increased PCAT-1 expression in CRC tissues. Increased PCAT-1 levels are associated with distant metastasis, and poorer overall survival. Multivariable Cox regression analysis identified PCAT-1 overexpression is an independent prognostic factor for CRC outcome. [55].

Some lncRNAs may also hold promise in the future as novel diagnostic biomarkers for CRC patients. lncRNA RP11-462C24.1 expression is decreased in CRC cancer tissues. Additionally, the levels of RP11-462C24.1 are decreased in CRC patients with metastatic disease. Multivariate analysis identified RP11-462C24.1 to be an independent predictor of patient prognosis. Decreased RP11-462C24.1 levels were also associated with decreased disease-free survival. RP11-462C24.1 may be a novel prognostic and diagnostic marker for CRC [56]. In addition, prostate cancer non-coding RNA 1 (PRNCR1) has also been investigated as a diagnostic marker for CRC. Yang et al investigated the clinical significance and biological function of PRNCR1 in CRC. In a cohort of 63 patients, PRNCR1 was significantly overexpressed in CRC tissues compared to adjacent control tissues, and PRNCR1 may be a sensitive diagnostic biomarker of CRC [57].

Liu et al demonstrated NEAT1 (nuclear-enriched abundant transcript 1) expression was increased in colorectal cancer, and positively associated with tumor differentiation, invasion, metastasis, and TNM stage. Increased NEAT1 expression levels were correlated with decreased patient survival. More importantly, Cox's proportional hazards analysis demonstrated increased NEAT1 expression was an independent prognostic marker of poor CRC patient outcome. Therefore, NEAT1 may be a CRC prognostic indicator [58]. Wu et al analyzed the expression of NEAT1 in blood, matched primary tumor 
Table 6: Clinical application

\begin{tabular}{|c|c|c|c|}
\hline LncRNA & $\begin{array}{l}\text { In colorectal cancer, its } \\
\text { expressions is: }\end{array}$ & Functions & Reference \\
\hline DANCR & Upregulated & $\begin{array}{l}\text { Serves as a potential prognosis } \\
\text { predictor for CRC patients, } \\
\text { associates with TNM stage, } \\
\text { histologic grade, and lymph node } \\
\text { metastasis, correlates with shorter } \\
\text { overall survival and disease-free } \\
\text { survival time. }\end{array}$ & {$[52]$} \\
\hline FTX & Upregulated & $\begin{array}{l}\text { Functions as an independent } \\
\text { prognostic factor for CRC patients, } \\
\text { associates with differentiation } \\
\text { grade, lymph vascular invasion, } \\
\text { and clinical stage, and predicts } \\
\text { poorer overall survival. }\end{array}$ & {$[53]$} \\
\hline PCAT-1 & Upregulated & $\begin{array}{l}\text { Serves as an independent } \\
\text { prognostic factor for CRC outcome } \\
\text { and indicates poorer overall } \\
\text { survival. }\end{array}$ & {$[54,55]$} \\
\hline RP11-462C24.1 & Downregulated & $\begin{array}{c}\text { Serves as a prognosis indicator } \\
\text { for CRC patients, associates with } \\
\text { distant metastasis and poor disease- } \\
\text { free survival. }\end{array}$ & {$[56]$} \\
\hline PRNCR1 & Upregulated & $\begin{array}{l}\text { Proved to be a sensitive diagnostic } \\
\text { biomarker of CRC. }\end{array}$ & {$[57]$} \\
\hline NEAT1 & Upregulated & $\begin{array}{c}\text { Serves as a diagnostic and } \\
\text { prognostic biomarker of overall } \\
\text { survival in CRC, associates with } \\
\text { tumor differentiation, invasion, } \\
\text { metastasis and TNM stage, and } \\
\text { correlates with shorter disease-free } \\
\text { survival time and overall survival } \\
\text { time. }\end{array}$ & {$[58,59]$} \\
\hline HOTTIP & Upregulated & $\begin{array}{l}\text { Predicts unfavorable prognosis for } \\
\text { CRC patients. }\end{array}$ & {$[37]$} \\
\hline
\end{tabular}

tissues, para-tumor tissues, metastatic tissues, and immune cells from CRC patients and normal controls. Whole blood NEAT1 expression was significantly increased in colorectal cancer patients. Moreover, an elevated expression of NEAT1 was also seen in neutrophils from CRC patients [59]. In this sense, whole blood NEAT1 expression may be a novel diagnostic, prognostic, and survival biomarker in colorectal cancer. Apart from that, Ren et al characterized the role of a new lncRNA HOTTIP (HOXA transcript at the distal tip) in CRC, and demonstrated HOTTIP was increased in CRC tissues, and positively correlated with clinical stage and distant metastasis. Multivariate analysis suggests HOTTIP overexpression to be an independent factor of poor CRC prognosis [37]. These lncRNAs are potentially valuable in clinical practice. However, there is still a long way for them to go from bench to bedside.

\section{CONCLUSION AND PERSPECTIVES}

More than 1.2 million patients are diagnosed annually with colorectal cancer, one of the most common human malignancies. Comprehension of the underlying molecular pathogenesis of the disease is urgently needed. It is now recognized that mutations within the noncoding genome are major determinants of human diseases [60]. LncRNAs, which occupy a large size of the noncoding genome, serve as important signals of specific cellular states, and can be employed to identify cellular pathologies such as cancer. In this review, we 
have carefully culled data supporting the use of lncRNAs for diagnostic, prognostic, and potentially therapeutic use for CRC patients. Currently, there remain significant gaps in our understanding of lncRNA function in CRC. The function of many lncRNAs in CRC development and progression remain unknown. Efforts devoted to elucidating the underlying molecular mechanisms of CRCspecific lncRNAs are warranted and necessary. Systematic identification of potentially important lncRNAs central to $\mathrm{CRC}$ pathophysiology is necessary to advance the medical treatment of CRC for generations to come.

\section{CONFLICTS OF INTEREST}

None to declare.

\section{ACKNOWLEDGMENTS}

This work was supported by grants from the National Natural Science Foundation of China (grant \#81402396), Sichuan Science-Technology Soft Sciences Project (grant \#2016ZR0086), Yi Yao Foundation of West China Second Hospital, Sichuan University (grant \#14H0563), and Direct Scientific Research Grants from West China Second Hospital, Sichuan University(grant \#KS021).

\section{REFERENCES}

1. Zhang L, Pickard K, Jenei V, Bullock MD, Bruce A, Mitter R, Kelly G, Paraskeva C, Strefford J, Primrose J, Thomas GJ, Packham G and Mirnezami AH. miR-153 supports colorectal cancer progression via pleiotropic effects that enhance invasion and chemotherapeutic resistance. Cancer Res. 2013; 73:6435-6447.

2. Eng C. Toxic effects and their management: daily clinical challenges in the treatment of colorectal cancer. Nat Rev Clin Oncol. 2009; 6: 207-218.

3. Cabili MN, Trapnell C, Goff L, Koziol M, Tazon-Vega B, Regev A and Rinn JL. Integrative annotation of human large intergenic noncoding RNAs reveals global properties and specific subclasses. Genes Dev. 2011; 25:1915-1927.

4. Quinn JJ, Zhang QC, Georgiev P, Ilik IA, Akhtar A and Chang HY. Rapid evolutionary turnover underlies conserved lncRNA-genome interactions. Genes Dev. 2016; 30:191-207.

5. Hanahan D and Weinberg RA. Hallmarks of cancer: the next generation. Cell. 2011; 144:646-674.

6. He X, Tan X, Wang X, Jin H, Liu L, Ma L, Yu H and Fan Z. C-Myc-activated long noncoding RNA CCAT1 promotes colon cancer cell proliferation and invasion. Tumor Biol. 2014; 35:12181-12188.

7. Takahashi Y, Sawada G, Kurashige J, Uchi R, Matsumura T, Ueo H, Takano Y, Eguchi H, Sudo T, Sugimachi $\mathrm{K}$, Yamamoto $\mathrm{H}$, Doki $\mathrm{Y}$, Mori $\mathrm{M}$ and Mimori $\mathrm{K}$.
Amplification of PVT-1 is involved in poor prognosis via apoptosis inhibition in colorectal cancers. Br J Cancer. 2014; 110:164-171.

8. Graham LD, Pedersen SK, Brown GS, Ho T, Kassir Z, Moynihan AT, Vizgoft EK, Dunne R, Pimlott L, Young GP, Lapointe LC and Molloy PL. Colorectal neoplasia differentially expressed (CRNDE), a novel gene with elevated expression in colorectal adenomas and adenocarcinomas. Genes Cancer. 2011; 2:829-840.

9. Ellis BC, Molloy PL and Graham LD. CRNDE: A long non-coding RNA involved in CanceR, Neurobiology, and DEvelopment. Front Genet. 2012; 3:270.

10. Ellis BC, Graham LD and Molloy PL. CRNDE, a long noncoding RNA responsive to insulin/IGF signaling, regulates genes involved in central metabolism. Biochim Biophys Acta. 2014; 1843:372-386.

11. Xu C, Yang M, Tian J, Wang X and Li Z. MALAT-1: a long non-coding RNA and its important 3' end functional motif in colorectal cancer metastasis. Int J Oncol. 2011; 39:169-175.

12. Ji Q, Zhang L, Liu X, Zhou L, Wang W, Han Z, Sui H, Tang Y, Wang Y, Liu N, Ren J, Hou F and Li Q. Long non-coding RNA MALAT1 promotes tumor growth and metastasis in colorectal cancer through binding to SFPQ and releasing oncogene PTBP2 from SFPQ/PTBP2 complex. Br J Cancer. 2014; 111:736-748.

13. Hu ZY, Wang XY, Guo WB, Xie LY, Huang YQ, Liu YP, Xiao LW, Li SN, Zhu HF, Li ZG and Kan H. Long noncoding RNA MALAT1 increases AKAP-9 expression by promoting SRPK1-catalyzed SRSF1 phosphorylation in colorectal cancer cells. Oncotarget. 2016; 7:1173311743. doi: 10.18632/oncotarget.7367.

14. Askarian-Amiri ME, Crawford J, French JD, Smart CE, Smith MA, Clark MB, Ru K, Mercer TR, Thompson ER, Lakhani SR, Vargas AC, Campbell IG, Brown MA, Dinger ME and Mattick JS. SNORD-host RNA Zfas 1 is a regulator of mammary development and a potential marker for breast cancer. RNA. 2011; 17:878-891.

15. Zhang Z, Weaver DL, Olsen D, deKay J, Peng Z, Ashikaga $\mathrm{T}$ and Evans MF. Long non-coding RNA chromogenic in situ hybridisation signal pattern correlation with breast tumor pathology. J Clin Pathol. 2016; 69:76-81.

16. Li T, Xie J, Shen C, Cheng D, Shi Y, Wu Z, Deng X, Chen H, Shen B, Peng C, Li H, Zhan Q and Zhu Z. Amplification of long noncoding RNA ZFAS1 promotes metastasis in hepatocellular carcinoma. Cancer Res. 2015; 75:3181-3191.

17. Thorenoor N, Faltejskova-Vychytilova P, Hombach S, Mlcochova J, Kretz M, Svoboda M and Slaby O. Long noncoding RNA ZFAS1 interacts with CDK1 and is involved in p53-dependent cell cycle control and apoptosis in colorectal cancer. Oncotarget. 2016; 7:622-637. doi: 10.18632/ oncotarget.5807.

18. Kim T, Jeon YJ, Cui R, Lee JH, Peng Y, Kim SH, Tili E, Alder $\mathrm{H}$ and Croce CM. Role of MYC-regulated long noncoding RNAs in cell cycle regulation and tumorigenesis. J Natl Cancer Inst. 2015; 107. 
19. Kim T, Cui R, Jeon YJ, Fadda P, Alder H and Croce CM. MYC-repressed long noncoding RNAs antagonize MYCinduced cell proliferation and cell cycle progression. Oncotarget. 2015; 6:18780-18789. doi: 10.18632/ oncotarget.3909.

20. Naemura M, Tsunoda T, Inoue $Y$, Okamoto H, Shirasawa S and Kotake Y. ANRIL regulates the proliferation of human colorectal cancer cells in both two- and three-dimensional culture. Mol Cell Biochem. 2016; 412:141-146.

21. Han Y, Yang YN, Yuan HH, Zhang TT, Sui H, Wei XL, Liu L, Huang P, Zhang WJ and Bai YX. UCA1, a long noncoding RNA upregulated in colorectal cancer influences cell proliferation, apoptosis and cell cycle distribution. Pathology. 2014; 46:396-401.

22. Ni B, Yu X, Guo X, Fan X, Yang Z, Wu P, Yuan Z, Deng Y, Wang J, Chen D and Wang L. Increased urothelial cancer associated 1 is associated with tumor proliferation and metastasis and predicts poor prognosis in colorectal cancer. Int J Oncol. 2015; 47:1329-1338.

23. Bian Z, Jin L, Zhang J, Yin Y, Quan C, Hu Y, Feng Y, Liu H, Fei B, Mao Y, Zhou L, Qi X, Huang S, Hua D, Xing C and Huang Z. LncRNA-UCA1 enhances cell proliferation and 5-fluorouracil resistance in colorectal cancer by inhibiting miR-204-5p. Sci Rep. 2016; 6:23892.

24. Shi Y, Liu Y, Wang J, Jie D, Yun T, Li W, Yan L, Wang K and Feng J. Downregulated Long Noncoding RNA BANCR Promotes the Proliferation of Colorectal Cancer Cells via Downregualtion of p21 Expression. PloS one. 2015; 10:e0122679.

25. Yin DD, Liu ZJ, Zhang E, Kong R, Zhang ZH and Guo RH. Decreased expression of long noncoding RNA MEG3 affects cell proliferation and predicts a poor prognosis in patients with colorectal cancer. Tumor Biol. 2015; 36:4851-4859.

26. Pasic I, Shlien A, Durbin AD, Stavropoulos DJ, Baskin B, Ray PN, Novokmet A and Malkin D. Recurrent focal copy-number changes and loss of heterozygosity implicate two noncoding RNAs and one tumor suppressor gene at chromosome 3q13.31 in osteosarcoma. Cancer Res. 2010; 70:160-171.

27. Qi P, Xu MD, Ni SJ, Huang D, Wei P, Tan C, Zhou XY and $\mathrm{Du}$ X. Low expression of LOC285194 is associated with poor prognosis in colorectal cancer. J Transl Med. 2013; 11:122.

28. Liu Q, Huang J, Zhou N, Zhang Z, Zhang A, Lu Z, Wu F and Mo YY. LncRNA loc285194 is a p53-regulated tumor suppressor. Nucleic Acids Res. 2013; 41:4976-4987.

29. Shi Y, Lu J, Zhou J, Tan X, He Y, Ding J, Tian Y, Wang L and Wang K. Long non-coding RNA Loc554202 regulates proliferation and migration in breast cancer cells. Biochem Biophys Res Commun. 2014; 446:448-453.

30. Augoff K, McCue B, Plow EF and Sossey-Alaoui K. miR31 and its host gene lncRNA LOC554202 are regulated by promoter hypermethylation in triple-negative breast cancer. Mol Cancer. 2012; 11:5.
31. Xi S, Yang M, Tao Y, Xu H, Shan J, Inchauste S, Zhang M, Mercedes L, Hong JA, Rao M and Schrump DS. Cigarette smoke induces C/EBP-beta-mediated activation of miR-31 in normal human respiratory epithelia and lung cancer cells. PloS one. 2010; 5:e13764.

32. Ding J, Lu B, Wang J, Wang J, Shi Y, Lian Y, Zhu Y, Wang J, Fan Y, Wang Z, De W and Wang K. Long non-coding RNA Loc554202 induces apoptosis in colorectal cancer cells via the caspase cleavage cascades. J Exp Clin Cancer Res. 2015; 34:100.

33. Guo Q, Zhao Y, Chen J, Hu J, Wang S, Zhang D and Sun Y. BRAF-activated long non-coding RNA contributes to colorectal cancer migration by inducing epithelialmesenchymal transition. Oncol Lett. 2014; 8:869-875.

34. Liang WC, $\mathrm{Fu} \mathrm{WM}$, Wong $\mathrm{CW}$, Wang Y, Wang WM, Hu GX, Zhang L, Xiao LJ, Wan DC, Zhang JF and Waye MM. The lncRNA H19 promotes epithelial to mesenchymal transition by functioning as miRNA sponges in colorectal cancer. Oncotarget. 2015; 6:22513-22525. doi: 10.18632/ oncotarget.4154.

35. Kogo R, Shimamura T, Mimori K, Kawahara K, Imoto S, Sudo T, Tanaka F, Shibata K, Suzuki A, Komune S, Miyano $\mathrm{S}$ and Mori M. Long noncoding RNA HOTAIR regulates polycomb-dependent chromatin modification and is associated with poor prognosis in colorectal cancers. Cancer Res. 2011; 71:6320-6326.

36. Wu ZH, Wang XL, Tang HM, Jiang T, Chen J, Lu S, Qiu GQ, Peng ZH and Yan DW. Long non-coding RNA HOTAIR is a powerful predictor of metastasis and poor prognosis and is associated with epithelial-mesenchymal transition in colon cancer. Oncol Rep. 2014; 32:395-402.

37. Ren YK, Xiao Y, Wan XB, Zhao YZ, Li J, Li Y, Han GS, Chen XB, Zou QY, Wang GC, Lu CM, Xu YC and Wang YC. Association of long non-coding RNA HOTTIP with progression and prognosis in colorectal cancer. Int J Clin Exp Pathol. 2015; 8:11458-11463.

38. Sun J, Ding C, Yang Z, Liu T, Zhang X, Zhao C and Wang J. The long non-coding RNA TUG1 indicates a poor prognosis for colorectal cancer and promotes metastasis by affecting epithelial-mesenchymal transition. J Transl Med. 2016; 14:42.

39. Chen N, Guo D, Xu Q, Yang M, Wang D, Peng M, Ding Y, Wang $\mathrm{S}$ and Zhou J. Long non-coding RNA FEZF1-AS1 facilitates cell proliferation and migration in colorectal carcinoma. Oncotarget. 2016; 7:11271-11283. doi: 10.18632/oncotarget.7168.

40. Zhang Z, Zhou C, Chang Y, Zhang Z, Hu Y, Zhang F, Lu Y, Zheng L, Zhang W, Li X and Li X. Long non-coding RNA CASC11 interacts with hnRNP-K and activates the WNT/ beta-catenin pathway to promote growth and metastasis in colorectal cancer. Cancer Lett. 2016; 376:62-73.

41. Deng Q, He B, Gao T, Pan Y, Sun H, Xu Y, Li R, Ying H, Wang F, Liu X, Chen J and Wang S. Up-regulation of $91 \mathrm{H}$ promotes tumor metastasis and predicts poor prognosis for patients with colorectal cancer. PloS one. 2014; 9:e103022. 
42. Yuan Z, Yu X, Ni B, Chen D, Yang Z, Huang J, Wang J, Chen $\mathrm{D}$ and Wang L. Overexpression of long non-coding RNACTD903 inhibits colorectal cancer invasion and migration by repressing Wnt/beta-catenin signaling and predicts favorable prognosis. Int J Oncol. 2016; 48:2675-2685.

43. Zhang ZY, Lu YX, Zhang ZY, Chang YY, Zheng L, Yuan L, Zhang F, Hu YH, Zhang WJ and Li XN. Loss of TINCR expression promotes proliferation, metastasis through activating EpCAM cleavage in colorectal cancer. Oncotarget. 2016. doi: 10.18632/oncotarget.8141.

44. Qi P, Xu MD, Ni SJ, Shen XH, Wei P, Huang D, Tan C, Sheng WQ, Zhou XY and Du X. Down-regulation of ncRAN, a long non-coding RNA, contributes to colorectal cancer cell migration and invasion and predicts poor overall survival for colorectal cancer patients. Mol Carcinog. 2015; 54:742-750.

45. Wan G, Liu Y, Han C, Zhang X and Lu X. Noncoding RNAs in DNA repair and genome integrity. Antioxid Redox Signal. 2014; 20:655-677.

46. Ling H, Spizzo R, Atlasi Y, Nicoloso M, Shimizu M, Redis RS, Nishida N, Gafa R, Song J, Guo Z, Ivan C, Barbarotto E, De Vries I, Zhang X, Ferracin M, Churchman M, et al. CCAT2, a novel noncoding RNA mapping to 8q24, underlies metastatic progression and chromosomal instability in colon cancer. Genome Res. 2013; 23:1446-1461.

47. Vermeulen L and Snippert HJ. Stem cell dynamics in homeostasis and cancer of the intestine. Nat Rev Cancer. 2014; 14:468-480.

48. Yao J, Li J, Geng P, Li Y, Chen H and Zhu Y. Knockdown of a HIF-2alpha promoter upstream long noncoding RNA impairs colorectal cancer stem cell properties in vitro through HIF-2alpha downregulation. Onco Targets Ther. $2015 ; 8: 3467-3474$.

49. Dou J, Ni Y, He X, Wu D, Li M, Wu S, Zhang R, Guo $\mathrm{M}$ and Zhao F. Decreasing lncRNA HOTAIR expression inhibits human colorectal cancer stem cells. Am J Tansl Res. 2016; 8:98-108.

50. Wang L, Bu P, Ai Y, Srinivasan T, Chen HJ, Xiang K, Lipkin SM and Shen X. A long non-coding RNA targets microRNA miR-34a to regulate colon cancer stem cell asymmetric division. eLife. 2016; 5.

51. Wang J, Lei ZJ, Guo Y, Wang T, Qin ZY, Xiao HL, Fan LL, Chen DF, Bian XW, Liu J and Wang B. miRNAregulated delivery of lincRNA-p21 suppresses beta-catenin signaling and tumorigenicity of colorectal cancer stem cells. Oncotarget. 2015; 6:37852-37870. doi: 10.18632/ oncotarget.5635.
52. Liu Y, Zhang M, Liang L, Li J and Chen YX. Overexpression of IncRNA DANCR is associated with advanced tumor progression and poor prognosis in patients with colorectal cancer. Int J Clin Exp Pathol. 2015; 8:11480-11484.

53. Guo XB, Hua Z, Li C, Peng LP, Wang JS, Wang B and Zhi QM. Biological significance of long non-coding RNA FTX expression in human colorectal cancer. Int J Clin Exp Med. 2015; 8:15591-15600.

54. Prensner JR, Iyer MK, Balbin OA, Dhanasekaran SM, Cao Q, Brenner JC, Laxman B, Asangani IA, Grasso CS, Kominsky HD, Cao X, Jing X, Wang X, Siddiqui J, Wei JT, Robinson D, et al. Transcriptome sequencing across a prostate cancer cohort identifies PCAT-1, an unannotated lincRNA implicated in disease progression. Nat Biotech. 2011; 29:742-749.

55. Ge X, Chen Y, Liao X, Liu D, Li F, Ruan H and Jia W. Overexpression of long noncoding RNA PCAT-1 is a novel biomarker of poor prognosis in patients with colorectal cancer. Med Oncol. 2013; 30:588.

56. Shi D, Zheng H, Zhuo C, Peng J, Li D, Xu Y, Li X, Cai $\mathrm{G}$ and Cai S. Low expression of novel lncRNA RP11$462 \mathrm{C} 24.1$ suggests a biomarker of poor prognosis in colorectal cancer. Med Oncol. 2014; 31:31.

57. Yang L, Qiu M, Xu Y, Wang J, Zheng Y, Li M, Xu L and Yin R. Upregulation of long non-coding RNA PRNCR1 in colorectal cancer promotes cell proliferation and cell cycle progression. Oncol Rep. 2016; 35:318-324.

58. Li Y, Li Y, Chen W, He F, Tan Z, Zheng J, Wang W, Zhao Q and Li J. NEAT expression is associated with tumor recurrence and unfavorable prognosis in colorectal cancer. Oncotarget. 2015; 6:27641-27650. doi: 10.18632/ oncotarget.4737.

59. Wu Y, Yang L, Zhao J, Li C, Nie J, Liu F, Zhuo C, Zheng Y, Li B, Wang Z and Xu Y. Nuclear-enriched abundant transcript 1 as a diagnostic and prognostic biomarker in colorectal cancer. Mol Cancer. 2015; 14:191.

60. Maurano MT, Humbert R, Rynes E, Thurman RE, Haugen E, Wang H, Reynolds AP, Sandstrom R, Qu H, Brody J, Shafer A, Neri F, Lee K, Kutyavin T, Stehling-Sun S, Johnson AK, et al. Systematic localization of common disease-associated variation in regulatory DNA. Science. 2012; 337:1190-1195.

61. Sun, Y., et al. (2016). "ANRIL is associated with the survival rate of patients with colorectal cancer, and affects cell migration and invasion in vitro." Mol Med Rep 14: 1714-1720. 